\title{
Protective Effects of Korean Herbal Remedy against Airway Inflammation in an Allergic Asthma by Suppressing Eosinophil Recruitment and Infiltration in Lung
}

\author{
Soyon Yoon ${ }^{1}$, Seokcheon Song ${ }^{1}$, Jae Woo Shin ${ }^{2}$, Sini Kang ${ }^{3}$, Hye Young Kim ${ }^{2, * \mathbb{D}}$ and Hyun Ju You ${ }^{1,4, *}$ \\ 1 Department of Environmental Health Sciences, Graduate School of Public Health, Seoul National University, \\ Seoul 08826, Korea; alex.sy.yoon@gmail.com (S.Y.); ursa20@snu.ac.kr (S.S.) \\ 2 Laboratory of Mucosal Immunology, Department of Biomedical Sciences, Seoul National University College \\ of Medicine, Seoul 110799, Korea; sinsin0818@snu.ac.kr \\ 3 Department of Food and Nutrition, Research Institute of Human Ecology, Seoul National University, \\ Seoul 08826, Korea; kangsini@snu.ac.kr \\ 4 Institute of Health and Environment, Graduate School of Public Health, Seoul National University, \\ Seoul 08826, Korea \\ * Correspondence: hykim11@snu.ac.kr (H.Y.K); dhlover1@snu.ac.kr (H.J.Y.); Tel.: +82-27-40-8970 (H.Y.K.); \\ +82-28-80-2790 (H.J.Y.)
}

check for updates

Citation: Yoon, S.; Song, S.; Shin, J.W.; Kang, S.; Kim, H.Y.; You, H.J. Protective Effects of Korean Herbal Remedy agains Airway Inflammation in an Allergic Asthma by Suppressing Eosinophil Recruitment and Infiltration in Lung. Antioxidants 2021, 10, 6. https:// dx.doi.org/10.3390/antiox10010006

Received: 31 October 2020

Accepted: 19 December 2020

Published: 23 December 2020

Publisher's Note: MDPI stays neutral with regard to jurisdictional claims in published maps and institutional affiliations.

Copyright: (c) 2020 by the authors. Licensee MDPI, Basel, Switzerland. This article is an open access article distributed under the terms and conditions of the Creative Commons Attribution (CC BY) license (https: / / creativecommons.org/ licenses/by/4.0/).

\begin{abstract}
The increasing prevalence of allergic asthma has become the world's major health issue. Current treatments for allergic asthma focus on treating symptoms, while permanent cures still remain undiscovered. In this study, we investigated the effect of Korean traditional herbal remedy, Pyunkang-tang (PGT) — composed of six plants—on asthma alleviation in a mouse model. The PGT mixture was orally gavaged to mice (PM group, $20 \mathrm{mg} / \mathrm{mouse} /$ day) from 7 days before sensitization with ovalbumin (OVA) (day -7$)$. On day 0 and day 14, mice from OVA-control $(n=9)$ and PM group $(n=8)$ were sensitized with OVA and alum through intraperitoneal injection. On days 18 20, OVA was challenged to mice through nasal injection and sacrificed next day. Cell profile in lung tissue was analyzed by flow cytometry and RT-qPCR analysis, and the number of eosinophils and expression of siglec- $F$ were significantly reduced in the PM group. Lung tissue was examined with hematoxylin and eosin (H\&E) and Alcian blue/periodic acid-Schiff (AB-PAS) staining. Noticeably reduced eosinophil infiltration around bronchioles was displayed in the PM group compared to the OVA-control group. Furthermore, PGT-treated mice showed a significant reduction in IL-13 and a mild reduction in IL-5 in lungs. A decreasing tendency of IL-5/13 (+) CD4+ T cells and IL-13(+) innate lymphoid cells (ILCs) and a significant reduction in IL5(+) ILCs were also observed. When treating PGT on murine lung epithelial cells stimulated by papain, there was a significant reduction in IL-33 mRNA expression levels. Taken together, oral delivery of PGT successfully alleviated asthmatic responses provoked by OVA in a mouse model and could lead to novel therapies for allergic asthma.
\end{abstract}

Keywords: phytochemical; allergic asthma; ovalbumin; innate lymphoid cell

\section{Introduction}

Asthma is a term widely used to describe a chronic inflammatory pulmonary disease characterized by various and recurrent symptoms which can have a wide extension of severity. Such symptoms include wheezing, coughing, reversible airflow obstruction and bronchospasm. Worldwide, about 339 million people suffer from asthma [1], and it contributes 13.8 million disability-adjusted life years (DALYs) annually [2]. Socio-economically, asthma is one of the major sources of global economic burden especially due to its high incidence, prevalence and the chronic nature [2-4].

Allergic asthma is the most common form of asthma that is often characterized by eosinophilic airway inflammation [5-7]. Type 2 helper cell (Th2) responses mainly drive the pathogenesis of the disease [8-10]; it is characterized by interleukin IL-5 and IL-13 
dependent lung eosinophilia, airway hyperresponsiveness (AHR), goblet cell hyperplasia, and IL-4 dependent immunoglobulin E (IgE) elevation in serum [7-14]. Current treatments for allergic asthma mainly focus on attenuating allergic responses upon allergen exposure. Inhaled steroids such as corticosteroids [15-17], monoclonal anti-IgE antibody [18-21] and bronchodilators $[22,23]$ are popular treatments, but their efficacy is restricted to reducing the symptoms without curing the disease $[14,17]$. Furthermore, these treatments are not effective for all patients [24,25]; there also are potential side effects [26-29]. As a result, there is an increasing demand for novel treatment strategies that are not restricted to reducing allergic responses, but rather that focus on attenuating the earlier stages of pathogenesis [14].

Complementary and alternative medicine (CAM) is termed, any medical and health care products or practices which are distinguished from standard medicines. Herbal remedies are one of the most popular methods among CAM to treat asthma, of which the use has increased dramatically worldwide in the past decades. Plant-based traditional medicine is an excellent example of herbal remedies, and there are increasing numbers of studies being conducted to prove the efficacy of traditional medicine on allergic asthma. More specifically, there is growing evidence that certain phytochemicals from traditional medicine have a significant effect on a variety of chronic diseases, including asthma.

Lonicerae Flos (LF), Liriopis Tuber (LT), Adenophorae Radix (AR), Xanthii Fructus (XF), Selaginellae Herba (SH), and Rehmanniae Radix Preparata (RRP) are parts of plant species (i.e., flowers, roots, fruits and leaves) which are common oriental medicinal herbs in Korea, Japan, and China. To be specific, LF can be considered as a source of natural antioxidants, which may be due to its chlorogenic acid component [30]. It has latent-heatclearing, antipyretic, detoxicant, and anti-inflammatory effects [31]. LT has shown to have the anti-inflammatory and anti-asthmatic effect [32]. AR modulates the activity of mast cells and respiratory mucous generation, and further exerts antitussive, expectorant, anti-asthmatic and anti-inflammatory effects [33,34]. Additionally, XF displays antioxidant, antinociceptive, and anti-inflammatory activities [35]. SH has been reported to relieve phlegm and asthma symptoms [36]. RRP has been widely utilized as an anti-inflammatory treatment [37].

A Korean traditional remedy called Pyunkang-tang (PGT), consisting of the six herbs mentioned above, has been used as traditional herbal medicine for managing the inflammatory hypersecretion of airway mucus present in chronic obstructive pulmonary disease (COPD), pneumonitis, tonsilitis, as well as pulmonary fibrosis for years [37]. PGT decreased the release of inflammatory cytokines in bronchoalveolar lavage fluid and mucus secretion in a rat COPD-like pulmonary inflammation model induced by mixture of cigarette smoke extract and sulfur dioxide [38]. Moreover, PGT showed alleviation of symptoms in patients suffering from asthma, atopic dermatitis, rhinitis, and food allergy [39].

In this study, we aimed to demonstrate the efficacy of the PGT mixture on alleviating ovalbumin (OVA)-induced allergic asthma in mice and to investigate the mechanism underlying reduced inflammation. Daily oral dosing with the PGT mixture abrogated the disease pathogenesis by decreasing infiltration of eosinophils in the lung. PGT reduced the Th2 response while not elevating the Th1 response. With its potential to modulate various immune responses, PGT can be further tested to be a novel therapeutic for allergic asthma.

\section{Materials and Methods}

\subsection{Preparation of Pyunkang-Tang (PGT) Mixture}

PGT is a water extract of six herbs (Table 1). The voucher specimens were deposited at the Herbarium of the College of Pharmacy, Kyung Hee University (Seoul, Korea). The six herbs were purchased from Dae-won-dang Oriental Drug Store (Seoul, Korea). The preparation of PGT water extract was conducted as previously described [37]. The $40 \mathrm{~g}$ of six herbal mixture were soaked in $500 \mathrm{~mL}$ of double-distilled deionized water and decocted for $150 \mathrm{~min}$ at $100{ }^{\circ} \mathrm{C}$ in a closed system. The extract was filtered through sterile gauze, concentrated in a rotary vacuum evaporator, lyophilized and stored at $-70{ }^{\circ} \mathrm{C}$ until tested. 
Approximately $615 \mathrm{mg}$ of lyophilized PGT extract mixture was prepared from $40 \mathrm{~g}$ of dried herbs (yield: 1.54\%). To develop the oral treatment of PGT to mice, the lyophilized PGT extract was prepared in phosphate saline buffer (PBS) at a final concentration of $100 \mathrm{mg} / \mathrm{mL}$.

Table 1. Composition of Pyunkang-tang (PGT) herbal remedy.

\begin{tabular}{|c|c|c|c|c|}
\hline Common Name & Genus & Family & Deposit No. & $\begin{array}{c}\text { Dry Weight } \\
\text { (g) }\end{array}$ \\
\hline $\begin{array}{l}\text { Lonicerae Flos } \\
\text { (flowers) }\end{array}$ & $\begin{array}{l}\text { Lonicerae japonica } \\
\text { Thunberg }\end{array}$ & Caprofoliaceae & $\begin{array}{l}\text { KHUOPS } \\
2013-75\end{array}$ & 4 \\
\hline $\begin{array}{l}\text { Liriopis Tuber } \\
\text { (underground } \\
\text { stem/roots) }\end{array}$ & $\begin{array}{l}\text { Liriope platyphylla } \\
\text { Wang et Tang }\end{array}$ & Liliaceae & $\begin{array}{l}\text { KHUOPS } \\
2013-76\end{array}$ & 4 \\
\hline $\begin{array}{l}\text { Adenophorae } \\
\text { Radix (roots) }\end{array}$ & $\begin{array}{l}\text { Adenophora triphilla } \\
\text { var. japonoica Hara }\end{array}$ & Campanulaceae & $\begin{array}{l}\text { KHUOPS } \\
2013-77\end{array}$ & 10 \\
\hline $\begin{array}{l}\text { Xanthii Fructus } \\
\text { (fruits) }\end{array}$ & $\begin{array}{c}\text { Xantium strumarinum } \\
\text { Linne }\end{array}$ & Compositae & $\begin{array}{l}\text { KHUOPS } \\
2013-78\end{array}$ & 10 \\
\hline $\begin{array}{l}\text { Selaginellae } \\
\text { Herba (leaves) }\end{array}$ & $\begin{array}{c}\text { Selaginella tamariscina } \\
\text { Spring }\end{array}$ & Selaginellaceae & $\begin{array}{l}\text { KHUOPS } \\
2013-79\end{array}$ & 10 \\
\hline $\begin{array}{c}\text { Rehmanniae } \\
\text { Radix Preparata } \\
\text { (roots) }\end{array}$ & $\begin{array}{c}\text { Rehmannia glutinosa } \\
\text { Liboschitz var. } \\
\text { purpurea Making }\end{array}$ & Scrophulariaceae & $\begin{array}{l}\text { KHUOPS } \\
2013-80\end{array}$ & 2 \\
\hline
\end{tabular}

\subsection{Non-Targeted Metabolites Analysis of PGT by UPLC/MS}

Lyophilized powder of PGT was dissolved in 99\% methanol at a final concentration of $1 \mathrm{mg} / \mathrm{mL}$. The subsequent solution was filter-sterilized using $0.22 \mu \mathrm{m}$ syringe filter. To investigate the exploratory and non-targeted metabolite profile of PGT extract, we applied the UPLC/MS method $[40,41]$ to phytochemicals and water-soluble components in PGT. Three PGT samples were analysed by qualitative metabolites profiling. An Acquity ultra-perforce liquid chromatography (UPLC, Waters, Milford, MA, USA) was used with a C18 BSH (130 ̊, $1.7 \mu \mathrm{m}, 2.1 \mathrm{~mm} \times 100 \mathrm{~mm})$ column (Waters). Preparation was conducted using solvent $\mathrm{A}(0.1 \% \mathrm{FA}$ in $100 \%$ high-grade water) and solvent $\mathrm{B}(0.1 \% \mathrm{FA}$ in $100 \%$ methanol). The flow rate was $0.176 \mathrm{~mL} / \mathrm{min}$ starting with $100 \%$ solvent $\mathrm{A}$ for $1 \mathrm{~min}$. Afterwards, a linear gradient was run in $59 \mathrm{~min}$ to $100 \%$ solvent $\mathrm{B}$. The post run was 5 min with $100 \%$ solvent $B$ and additional 10 min with $100 \%$ solvent $A$ for re-equilibration. Mass spectrometry (MS) was performed using a Synapt G2-S mass instrument (Waters) equipped with an electrospray ion (ESI) source operated in high-resolution mode (ESI+, positive) or (ESI-, negative) mode. All mass spectral data were collected in centroid mode using the MSe mode of operation The column temperature was $52{ }^{\circ} \mathrm{C}$ and the injection volume was $10 \mu \mathrm{L}$. The separation of peaks in the PGT extract was checked on a diode array detector. The total ion chromatogram (TIC) and the base peak chromatogram (BPI) were displayed by MS measurement. In this study, the MS was set to positive ESI mode with a scan range from 50-2000, because the nitrogen-containing compounds would be abundant in herbs and plants. The capillary voltage was $3 \mathrm{kV}$. The sampling cone was set to 30 and the extraction cone to 3.0. Source temperature was set to $120^{\circ} \mathrm{C}$ and desolvation temperature to $450^{\circ} \mathrm{C}$. The flow of the cone gas was $10 \mathrm{~L} / \mathrm{h}$ and of the desolvation gas $800 \mathrm{~L} / \mathrm{h}$. The instrument was calibrated before analysis with $0.5 \mathrm{mM}$ sodium formate solution. The identification of selected components and data preprocessing was performed using MassLynx ${ }^{\mathrm{TM}}$ V4.1 (Waters Corp., Milford, MA, USA) software, version 4.1.

\subsection{Ovalbumin-Induced Allergic Asthma in a Mouse Model and PGT Mixture Treatment}

Six weeks old female BALB/c mice were purchased from Orient Bio Inc. (Seongnam, Korea). Upon arrival, mice were randomly allocated to individually ventilated cages that have available portable water and food ad libitum. Mice were kept in a semi specific pathogen-free facility at Seoul National University (Seoul, Korea). To investigate the effect of 
PGT mixture, we used a mouse model of allergic asthma induced by ovalbumin (OVA) and aluminium hydroxide (alum) [42]. Mice were divided into three groups: saline-challenged PBS treatment group (naïve, No-OVA-PBS, $n=8$ ), OVA-challenged PBS treatment group (vehicle control, OVA-PBS, $n=9$ ) and OVA-challenged PGT mixture treatment group (OVA-PM, $n=8$ ).

As shown in Figure 1, the PM group received daily oral gavage of $20 \mathrm{mg}$ of PGT in $200 \mu \mathrm{L}$ PBS from day -7 to day 20. The dosage was calculated based on the usual dosage for human in Korean Medicine Clinic. At the first week (day 0) and the third week (day 14) after oral administration, mice from OVA-control $(n=9)$ and PM group $(n=8)$ were sensitized with OVA and alum. Sensitization was conducted through intraperitoneal injection of $20 \mu \mathrm{g}$ ovalbumin (OVA) (Sigma Aldrich, St. Louis, MO, USA) absorbed in $2 \mu \mathrm{g}$ of Imject ${ }^{\circledR}$ Alum (Thermo Fisher Scientific, Waltham, MA, USA) on days 0 and 14. On days 18,19 and 20, mice were challenged intranasally with $50 \mu \mathrm{g}$ of OVA. On day 21 , animals were sacrificed, followed by collection of blood and lung tissue for further analysis. All experiments were in accordance with the Seoul National University Institutional Animal Care and Use Committee (IACUC) guidelines (No. SNU-170116-4). Mice were sacrificed at the end of experimentation by isoflurane (Hana Pharm Co., Ltd., Seoul, Korea) anesthesia and cervical dislocation.

21-day Ovalbumin (OVA)-induced allergic asthma model.

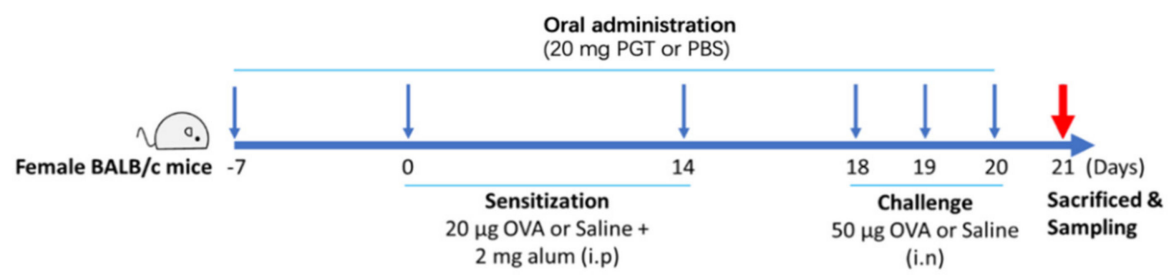

Figure 1. Experimental process diagram.

\subsection{Isolation of Lung and Histological Analysis}

Lungs were used for histopathological examination as previously described [43]. Briefly, twenty-four hours after final OVA challenge, right middle lobes were removed by dissection and fixed in 10\% neutral buffered formalin (Sigma Aldrich, St. Louis, MO, USA). The fixed tissue was embedded in paraffin and sectioned at $5 \mu \mathrm{m}$. Lung tissue sections were stained with hematoxylin and eosin stain (H\&E) for general morphology and identification of eosinophilia and with Alcian blue/periodic acid-Schiff (AB-PAS) for the identification of mucous and goblet cells in the epithelium. The preparation of paraffin block and staining of tissue section were prepared by Logone Bio., Inc. (Seoul, Korea). The stained tissue was observed under microscope equipped with slide scanner SNC400F (Leica Biosystems, Buffalo Grove, IL, USA) and representative images of 3 mice/group were selected. The number of eosinophils was calculated by a blind expert examination.

\subsection{RNA Preparation and Quantitative Reverse Transcriptase-Polymerase Chain Reaction (qRT-PCR)}

To further investigate the mechanism related to the reduction in eosinophilia in the PGT treatment, we examined the gene expression levels, transcription factors, and a surface marker in lung tissues. After $24 \mathrm{~h}$ from last challenge (on day 21), the mouse lung was collected in RNAlater $^{\circledR}$ (Ambion, Inc., Austin, TX, USA) solution (500 $\mu \mathrm{L} / 200 \mathrm{mg}$ lung tissue) and stored $-70{ }^{\circ} \mathrm{C}$ until analysis. RNA was extracted from lung tissue using easy-spin $^{\mathrm{TM}}$ (DNA free) Total RNA Extraction Kit (iNtRON Biotechnology, Seoul, Korea). Complementary DNA (cDNA) was synthesized using a High-Capacity cDNA Reverse Transcription Kit (Thermo Fisher Scientific, San Jose, CA, USA). Synthesized cDNA was used to perform quantitative PCR with Power SYBR ${ }^{\circledR}$ Green Master Mix (Thermo Fisher Scientific, San Jose, CA, USA) on the Applied Biosystems ${ }^{\mathrm{TM}}$ QuantStudio $^{\mathrm{TM}} 6$ Flex Real- 
Time PCR System (Applied Biosystems, Foster City, CA, USA). Primer sequences are shown in Supplementary Table S1.

\subsection{Determination of Serum $\operatorname{IgE}$}

After $24 \mathrm{~h}$ from last challenge (on day 21), blood was collected by cardiac puncture immediately after mice were anaesthetised by isoflurane. The blood was coagulated for $30 \mathrm{~min}$ at room temperature and centrifuged subsequently at $13,000 \times g$ for $5 \mathrm{~min}$. Collected serum was stored at $-80{ }^{\circ} \mathrm{C}$ until further analysis. LEGEND MAX ${ }^{\mathrm{TM}}$ Mouse OVA Specific IgE ELISA Kit (Biolegend, San Diego, CA, USA) was used to quantify the IgE levels in serum. The assay was performed according to the manufacturer's instructions.

\subsection{Flow Cytometry Analysis}

Murine lungs were chopped and incubated in RPMI1640 media with $1 \mathrm{mg} / \mathrm{mL}$ type IV collagenase (Worthington BioChem, Lakewood, NJ, USA) for at least $1 \mathrm{~h} 30 \mathrm{~min}$ at $37^{\circ} \mathrm{C}$. Red blood cells (RBC) were lysed using RBC lysis buffer (Biolegend, San Diego, CA, USA). Lung single cells were stained with following fluorochrome-conjugated antibodies. For surface staining, the following antibodies were used. Anti-CD45 (30-F11), Anti-CD3e (1452C11), anti-CD11c (HL3), anti-CD11b (M1/70), anti-CD19 (ID3), anti-CD49b (DX5), antiFceRI $\alpha$ (MAR-1), anti-CD90,2 (30-H12), anti-F4/80 (BM8) and anti-Ly6G (1A8), purchased from Biolegend. Anti-SiglecF (E50-2440) was purchased from BD Bioscience (San Diego, CA, USA). For intracellular staining, the following antibodies were used: anti-IL5 (TRFK5) and anti-IL17A (TC11-18H10.1), purchased from Biolegend (San Diego, CA, USA). AntiIL13 (eBio13A) was purchased from Thermo Fisher Scientific. For intracellular staining, a Fixation/Permeabilization Solution Kit with BD GolgiPlug (BD Biosciences, San Diego, CA, USA) was used following the manufacturer's protocol. Flow cytometry was carried out using LSRFortessa ${ }^{\mathrm{TM}}$ X-20 (BD biosciences, San Jose, CA, USA) and analyzed by FlowJo (V10.2) software (BD biosciences, San Jose, CA, USA). The gating strategy for immune cell population was represented in Supplementary Figure S1.

\subsection{In Vitro Experiment with Lung Epithelial Cells and Allergen}

Murine lung epithelial cells (MLE-12 ATCC ${ }^{\circledR}$ CRL-2110 ${ }^{\mathrm{TM}}$ ) were obtained from the American Type Culture Collection (ATCC, Manasaas, VA, USA) and cultured in DMEM/F12 medium with the following supplements: $5 \mu \mathrm{g} / \mathrm{mL}$ insulin, $10 \mu \mathrm{g} / \mathrm{mL}$ apo-transferrin, 30nM sodium selenite, $10 \mathrm{nM}$ hydrocortisone, $10 \mathrm{nM} \beta$-estradiol, $2 \mathrm{mM}$ L-glutamine, $10 \mathrm{mM}$ HEPES, and 10\% fetal bovine serum. Papain (Sigma-Aldrich, St Louis, MO, USA) was reconstituted with sterile PBS to $1 \mathrm{mg} / \mathrm{mL}$ and stored at $-20^{\circ} \mathrm{C}$. In this study, cells were treated with $0.25 \mathrm{mg} / \mathrm{mL}$ of papain for stimulation. After $9 \mathrm{~h}$, the cells were collected and lysed. mRNA was extracted using easy-spin ${ }^{\mathrm{TM}}$ (DNA free) Total RNA Extraction Kit (iNtRON Biotechnology, Seongnam, Korea) and complementary DNA (cDNA) was synthesized subsequently using Topscript ${ }^{\mathrm{TM}}$ RT DryMIX (enzynomics, Daejeon, Korea).

\subsection{Statistical Analysis}

Differences between each group were compared using unpaired Student's $t$-test, as appropriate, or one-way analysis of variance (version 8.0, GraphPad software, San Diego, CA, USA). In all experiments, the sample size of each group was $n=8,9$, and 8 in salinechallenged PBS treatment group (naïve, No-OVA-PBS), OVA-challenged PBS treatment group (vehicle control, OVA-PBS), and OVA-challenged PGT mixture treatment group (OVA-PM), respectively. All values are expressed as means \pm standard error of the mean (SEM). Statistical difference was accepted at $p<0.05$.

\section{Results}

\subsection{Non-Target Metabolites Profiling of PGT}

A total of 793 compounds were identified from the PGT extract, as shown in Supplementary Table S2. The non-targeted metabolites analysis with UPLC and high-resolution 
mass spectrometry showed a qualitative global profiling showed different classes of herbal components including peptides, sugars, organic acids and a variety of derivatives of alkaloids, saponins, flavonoids, phenols, and plant glycosides.

\subsection{PGT Treatment Suppressed Airway Inflammation, Mucous Production and Goblet Cell Hyperplasia in OVA-Induced Allergic Asthma Model}

During the study, there was no morbidity or mortality observed in any treatment groups. As expected, in OVA-challenged mice, eosinophil infiltration in the perivascular and peribronchial areas (H\&E staining) and overproduction of mucous and goblet cell hyperplasia (AB-PAS staining) were observed (Figure 2a). In PGT-treated mice, the eosinophil infiltration was markedly reduced, and the overproduction of mucous and goblet cell hyperplasia was suppressed (Figure 2a). While no infiltrated eosinophil was observed in the bronchioles of PBS-challenged mice, increased eosinophil counts were found in OVA-challenged mice (Figure 2b). PGT-treated mice showed a significant reduction in the number of eosinophils in comparison to PBS-treated mice. The level of serum immunoglobulin E (IgE) in PGT treatment mice was reduced in comparison to OVA-challenged PBS treatment mice (Figure 2c).

(a)

H\&E
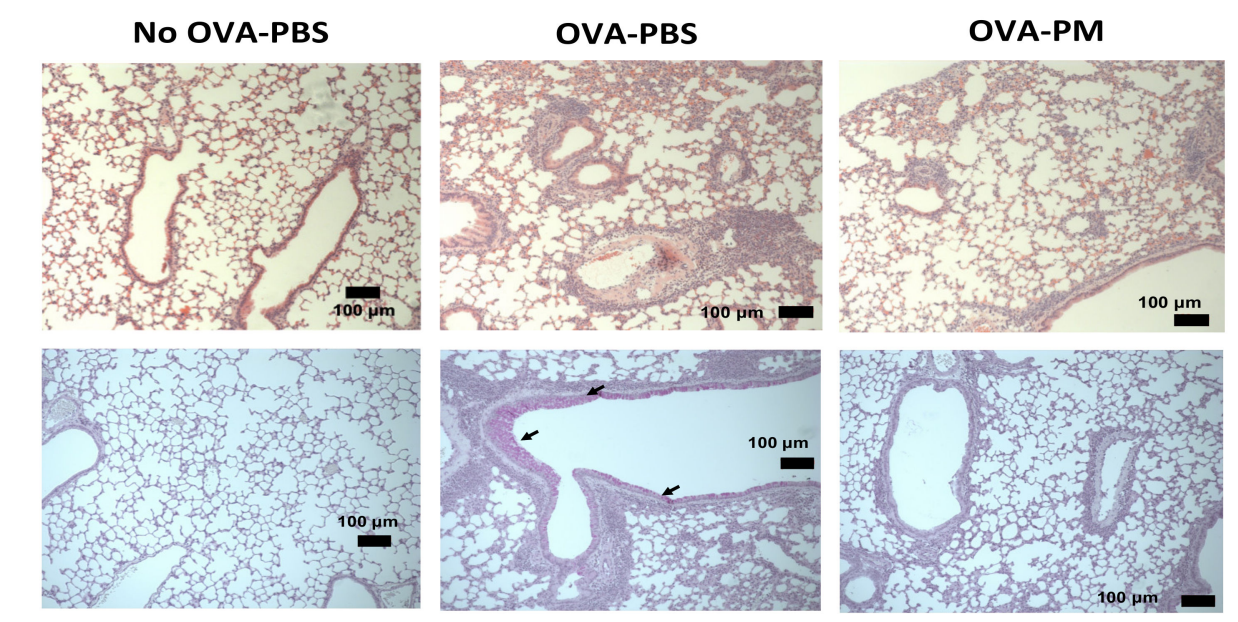

(b)

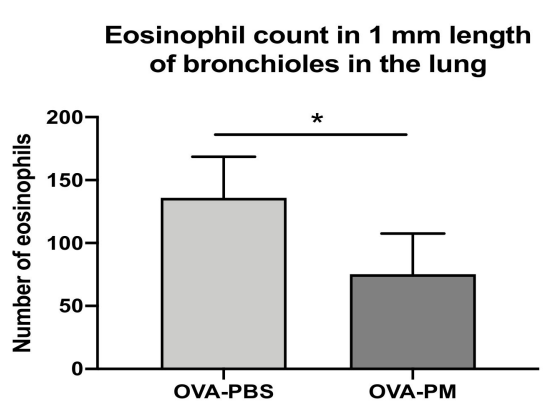

(c)

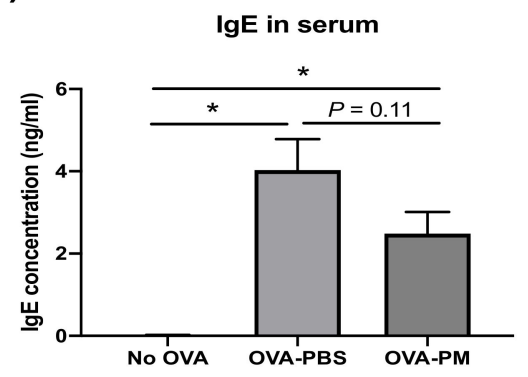

Figure 2. Experimental scheme and effect of PGT on lung histopathology, eosinophil counts in bronchioles in the lung, and $\operatorname{lgE}$ levels in serum of mice. Experimental scheme. (a) Representative scans of hematoxylin and eosin (H\&E) and periodic acid-Schiff (PAS) stained formalin-fixed paraffin-embedded sections of right middle lobe of lungs. (b) Number of eosinophils counted in $1 \mathrm{~mm}$ length of bronchioles in the lung from H\&E stained formalin-fixed paraffin-embedded sections. (c) Immunoglobulin E (IgE) levels in serum of mice. Capped bars illustrate the maximum data points within each treatment group. No OVA-PBS group, naïve mouse with PBS oral gavage; OVA-PBS group, OVA-sensitized with PBS oral gavage; OVA-PM group, OVA-sensitized with PGT oral gavage. Data are represented as means \pm standard error of the mean (SEM). ${ }^{*} p<0.05$. 


\subsection{PGT Treatment Alleviated Eosinophilia Infiltration in Lung}

Flow cytometry analysis was performed to examine CD $45^{\text {high }}$ myeloid cell populations in the lung, which can be used as key markers of pathogenesis of allergic asthmatic inflammation. The populations of eosinophils and neutrophils increased in both OVAchallenged groups (Figure 3a). In contrast, alveolar macrophages (AM) were significantly reduced by OVA challenge. Interestingly, both PBS- and OVA-challenged mice showed no difference in neutrophil populations. All OVA-challenged groups had significantly higher numbers of CD45+ cells than PBS-challenged group (Figure 3b). However, the PGT treatment group (OVA-PM) showed reduced eosinophils in the lung compared to OVA-challenged PBS treatment mice (Figure 3c). This reduction in eosinophils in PGT treatment mice was further confirmed by using RT-PCR analysis (Figure 3d). In OVAchallenged mice, the levels of Siglec-F, T-bet and Foxp3 mRNA expression were enhanced in comparison with the PBS-challenged mice; no difference in the levels of GATA-3 and ROR $\gamma t$ was detected. In PGT treated mice, we observed a significant reduction in the levels of T-bet and Foxp3, transcription factors which induce type 1 helper cell (Th1) and T regulatory (Treg) cells, respectively. Notably, the expression of Siglec-F, the prominent biomarker of eosinophils, significantly abrogated on a level comparable to that in PBS-challenged group. Both OVA-challenged groups showed a trend to reduce the gene expression of kit, the mast cell activation marker.

\subsection{PGT Treatment Reduced Production of IL-5 and IL-13 in Lung}

Flow cytometry analysis of lung lymphocytes was performed to further investigate the mechanisms underlying population change in lung eosinophils made by OVA-induced allergic airway inflammation. We also aimed to detect if the cytokine expression patterns in the lung occurred in correspondence with what we observed in Figure $3 b, c$. Flow cytometry results displayed increased total amounts of IL-13 and IL-5 in OVA-challenged mice in comparison to PBS-challenged group (Figure 4b). PGT treated mice showed a significant reduction in total IL-5 and IL-13 in lung lymphocytes. Interestingly, despite being a Th2 cytokine, the total amount of IL-4 in lung lymphocytes remained unchanged after the OVA challenge (Figure 4c). We examined the total amount of inflammatory cytokines in lung lymphocytes. Both PBS- and OVA-challenged mice displayed no difference in total amount of Interferon (IFN)- $\gamma$, a proinflammatory cytokine, which is produced by Th1 CD4+ cells, in lung lymphocytes (Figure 4d). Next, using RT-PCR, we investigated mRNA relative expression of $I l-10$, a prominent anti-inflammatory cytokine produced by Treg cells. The expression of Il-10 increased in both OVA-challenged groups, however, no difference was observed between two groups (Figure 4e).

\subsection{PGT Treatment Significantly Reduced IL-5-Producing Innate Lymphoid Cells}

We confirmed that the OVA-induced allergic asthma is mainly driven by the Th2 response, following the production of IL-5 and IL-13, but not IL-4, and that PGT treatment greatly reduced such induction. We then investigated which immune cell populations were targeted by PGT. Interestingly, we detected no difference in the composition of CD4+ $\mathrm{T}$ cell populations among PBS-challenged groups and OVA-challenged groups (Figure 5a). Still, although not statistically significant, there was a trend which suggested a reduced population of IL-5 and IL-13 producing CD4+ T cells in the PGT treatment group (Figure 5b). Next, we sought for different groups of cells in addition to T lymphocytes that can produce IL-5 and IL-13. We thus investigated how OVA-induced allergic asthma changed innate lymphoid cells (ILCs) in the lungs (Figure 5b). Interestingly, populations of IL-5 producing ILCs were significantly reduced in the PGT treatment group compared with the OVA-challenged control groups (Figure $5 b$ ). Overall, the results of immune profile analysis showed that PGT treatment reduced the populations of IL-5 and IL-13 producing immune cells, such as CD4+ T cells and ILCs, as well as the total amount of IL-5 and IL-13 producing cells in OVA-induced allergic asthma. 
(a)

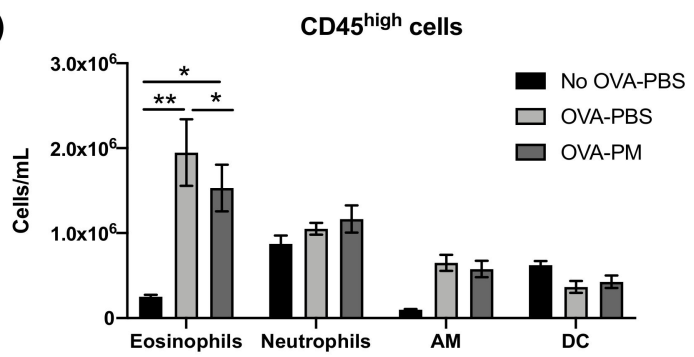

(b)

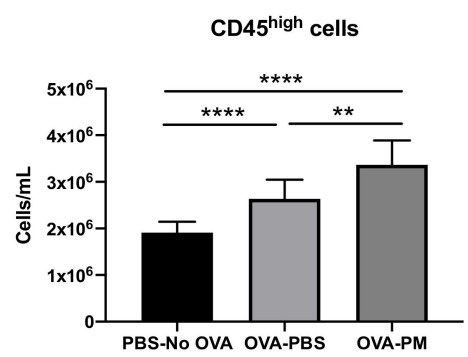

(c)
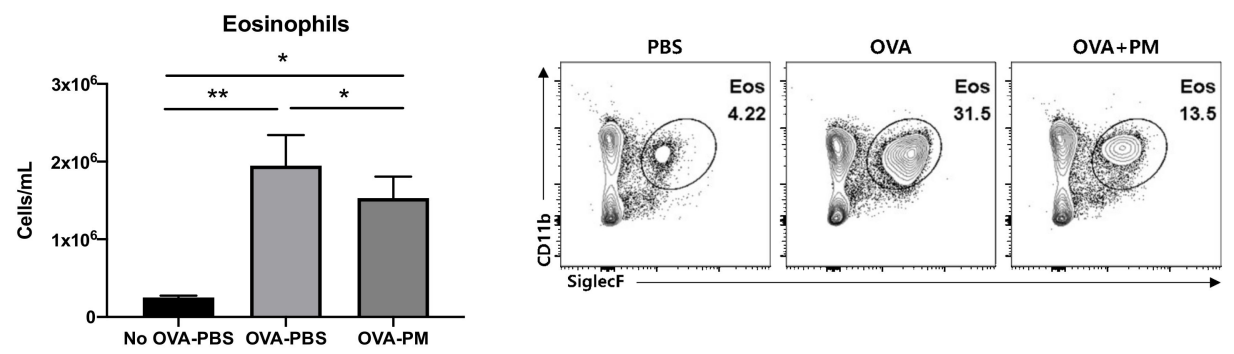

(d)

Surface markers and transcription factors

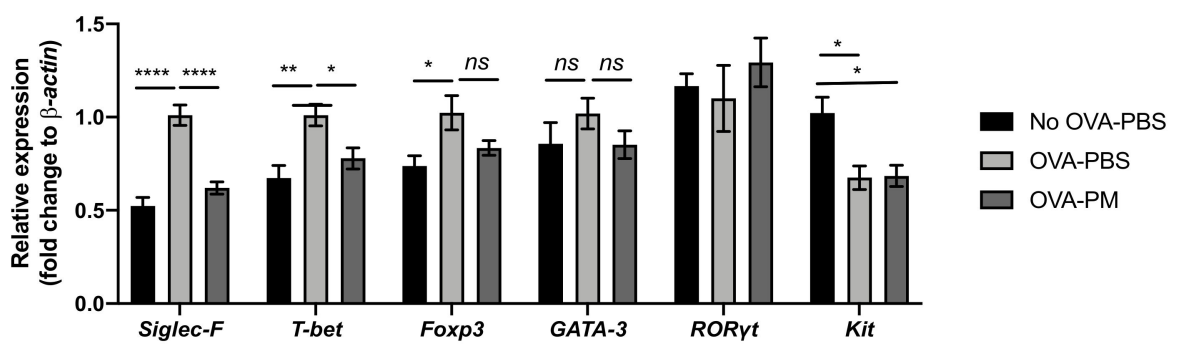

Figure 3. Effect of PGT on lung cell CD45+ counts and gene expression of surface markers and transcription factors. Lung cell counts of mice challenged with OVA, and treated with PGT, with samples collected $24 \mathrm{~h}$ after final challenge. (a) CD45+ cell subtype counts of each treatment group. (b) Total CD45+ cell counts. (c) Total eosinophils counts and representative flow cytometry analysis plots of treatment group. (d) Relative gene expression levels of cell surface markers and transcription factors in the lung. $\beta$-actin was used as a housekeeping gene. No OVA-PBS group, naïve mouse with PBS oral gavage; OVA-PBS group, OVA-sensitization and PBS oral gavage; OVA-PM group, OVA-sensitization and PGT oral gavage. Data are represented as means \pm standard error of the mean (SEM). AM, alveolar macrophages; DC, dendritic cells. ${ }^{*} p<0.05$, ${ }^{* *} p<0.01,{ }^{* * * *} p<0.0001$.

3.6. PGT Treatment Suppressed Production of IL-33, But not TSLP, in Murine Lung Epithelial Cells after Papain Stimulation

A significant reduction in IL-5(+) ILC cell populations, shown in Figure 5, led us to conduct a further investigation of the mechanism through which PGT induced such a change. We set up an in vitro experiment using MLE-12 cells, using papain as stimulant. Notably, PGT treatment significantly reduced IL-33 mRNA expression, to an even greater degree than the control treatment (Figure 6a) in the absence of papain stimulation. Under the papain stimulation, addition of PGT significantly reduced the IL-33 mRNA expression. In contrast, thymic stromal lymphopoietin (TSLP), another cytokine produced by lung epithelial tissue under allergen stimulation (Figure 6b), showing that the PGT specifically targets the production of IL-33. A possible mechanism of PGT on alleviation of airway inflammation, by supressing asthmatic eosinophil recruitment and infiltration in the lung, is represented in Figure 6c. 

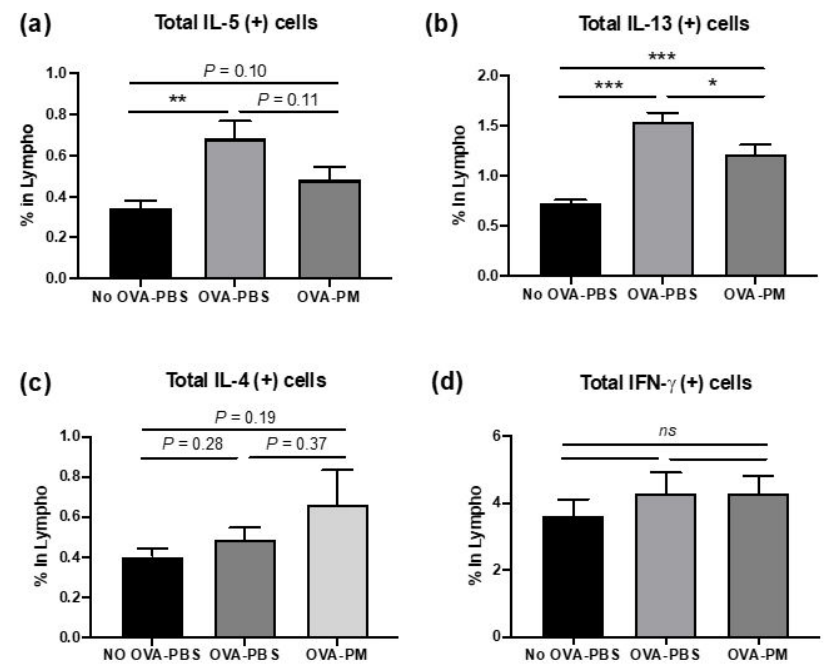

(d)
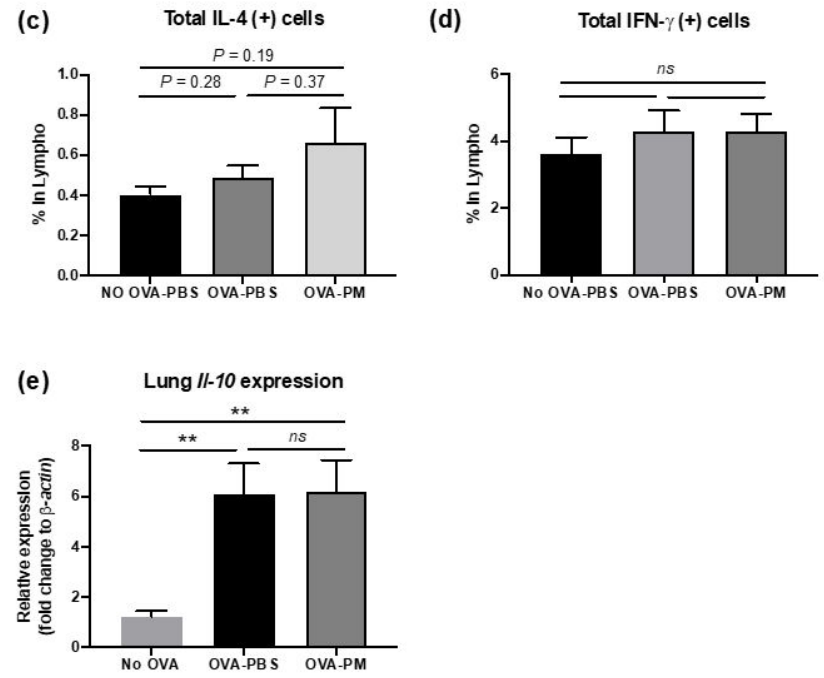

Figure 4. Impact on PGT on lung inflammatory mediators. Percentages of cytokine producing lymphocytes were determined using Fluorescence-activated Cell Sorting (FACS) analysis in lungs of mice challenged with OVA, and treated with PGT, with samples collected $24 \mathrm{~h}$ after final challenge. (a) \% total IL-5 producing lymphocytes. (b) \% total IL-13 producing lymphocytes. (c) \% total IL-4 producing lymphocytes. (d) \% total IFN- $\gamma$ producing lymphocytes. (e) Relative expression level of Il-10 in lungs determined through RT-qPCR using $\beta$-actin as a housekeeping gene. No OVA-PBS group, naïve mouse with PBS oral gavage; OVA-PBS group, OVA-sensitization and PBS oral gavage; OVA-PM group, OVA-sensitization and PGT oral gavage. Data are represented as means \pm standard error of the mean (SEM) ${ }^{*} p<0.05,{ }^{* *} p<0.01,{ }^{* * *} p<0.001$.

(a)

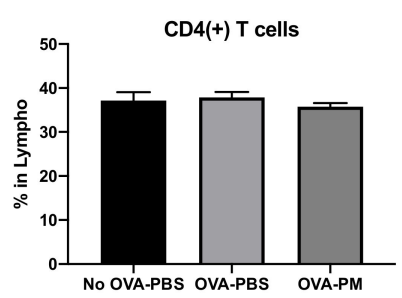

(b)

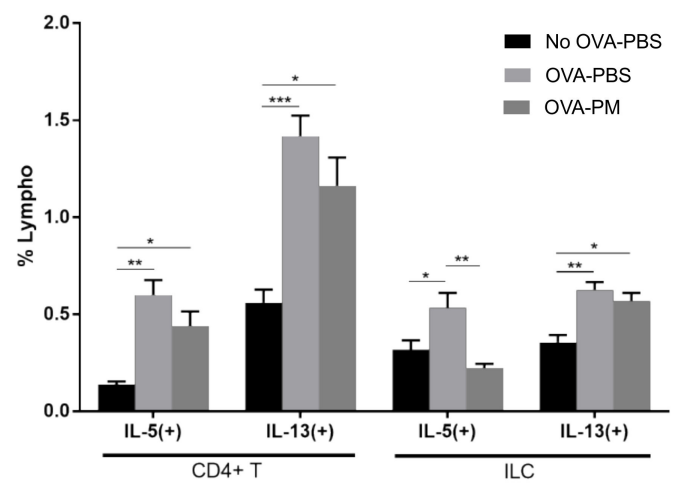

Figure 5. Impact of PGT on populations of CD4+ T cells and innate lymphoid cells (ILCs). Population of cells in lungs of mice challenged with OVA, and treated with PGT, with samples collected $24 \mathrm{~h}$ after final challenge. Percentages of cytokine producing lymphocytes were determined using Fluorescence-activated Cell Sorting (FACS). (a) \% of total CD4+ T cells, (b) IL-5(+) and IL-13(+) subtypes of CD4+ T cells (left) and ILCs (right). No OVA-PBS group, naïve mouse with PBS oral gavage; OVA-PBS group, OVA-sensitization and PBS oral gavage; OVA-PM group, OVA-sensitization and PGT oral gavage. Data are represented as means \pm standard error of the mean (SEM) ${ }^{*} p<0.05,{ }^{* *} p<0.01,{ }^{* * *} p<0.001$. 
(a)

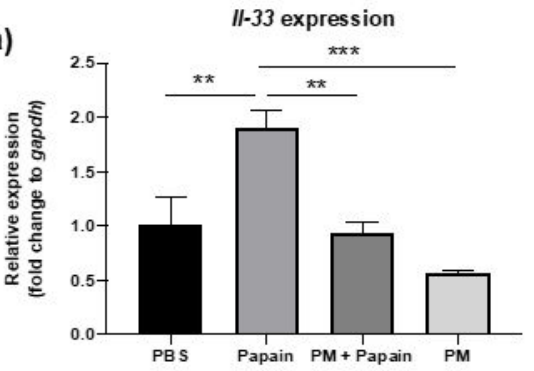

(b)

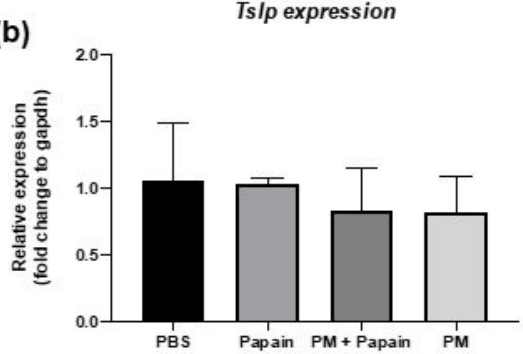

(c)

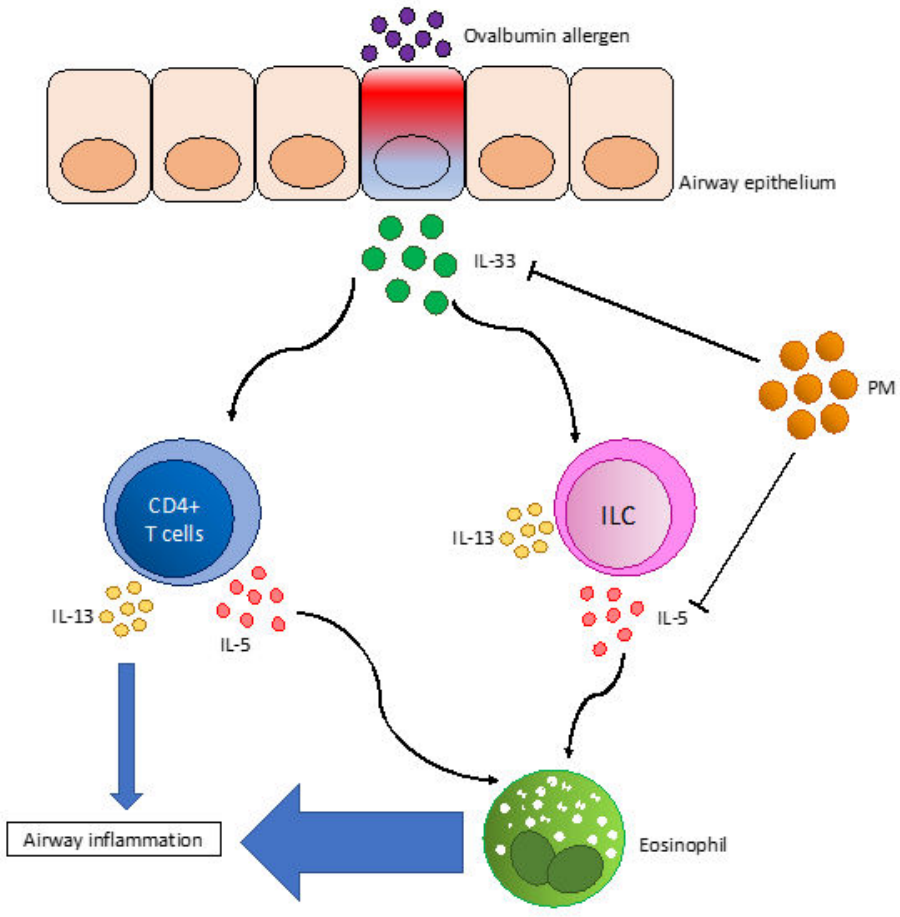

Figure 6. Effects of PGT on IL-33 (a) and thymic stromal lymphopoietin (TSLP) (b) expression in epithelial cells in vitro, and schematic diagram of its plausible mechanism (c). MLE-12 cells were grown to confluence and stimulated with PBS or papain $(0.25 \mathrm{mg} / \mathrm{mL})$, followed by either PBS or PGT $(1 \mathrm{mg} / \mathrm{mL})$ treatment. Cells were harvested after $9 \mathrm{~h}$. Gapdh gene was used to normalize the expression levels between groups. PBS group, PBS and PBS treated; papain group, papain and PBS treated; PM+papain group, papain and PGT treated; PM group, PBS and PGT treated. Data are represented with means \pm standard error of the mean (SEM). ${ }^{* *} p<0.01$, ${ }^{* * *} p<0.001$.

\section{Discussion}

In this study, we demonstrated the effect of PGT on significantly reducing the disease pathogenesis in OVA-induced allergic asthma model in mice. As an exploratory experiment, we also performed the global non-target metabolites profiling using UPLC-MS analysis to provide an overview of the constituents in complex herbal remedies. Although a total of 793 compounds were identified from the data of three PGT samples, it is difficult to conclude which molecules are active components of PGT, exerting anti-asthmatic functions. However, qualitative characterization of the herbal mixture could be applied for comparative analysis of different plant compounds and quantitative assessment of bioactive compounds in further studies.

Ovalbumin is a well-characterized and widely-used allergen to induce acute allergic asthma in mice. OVA induction increased pulmonary inflammatory infiltrates, despite the reduction in alveolar macrophages. However, a striking effect of PGT on the significant reduction in lung eosinophilia was confirmed through lung histopathology and flow 
cytometry. This suggests that the disease was induced in a strongly eosinophil-dependent manner. Consistent with this finding, a significant reduction in mRNA expression levels of siglec- $F$, a surface marker of eosinophil which is used to regulate levels of eosinophils, was also observed.

Our flow cytometry results revealed that the effects of PGT on reducing OVA-induced eosinophilia are closely related with regulating the levels of IL-5 and IL-13 in the lung. Previous studies have shown that various types of helper T cells contribute to the pathogenesis of allergic asthma [38-40]. Multiple mechanisms have been proposed to provide insight into our understanding of the development of the disease and resulting phenotypes, which eventually, suggest potential therapeutic targets. Th2 asthma hypothesis, which is the most prominently used to explain the disease development, is based on dysregulation of the Th1/Th2 balance [41]. It states that IgE and eosinophils are regulated by Th2 cytokines and play a major part in disease pathogenesis. Th2 cells activated by allergen produce Th2 cytokines, mainly IL-4, IL-5 and IL-13, which leads to eosinophilic lung inflammation, goblet cell hyperplasia, and mucous production. The recruitment of eosinophils in the lung and the degree of eosinophilia are closely related to AHR.

IL-5 is a cytokine which has a high specificity for eosinophil production, differentiation and activation. The prime source of IL-5 is Th2 lymphocytes of adaptive immunity as the Th2 hypothesis states, but other sources of IL-5 are also present. ILC2 have been reported to significantly contribute to IL-5 and IL-13 production, thus activating and recruiting eosinophils [42]. ILCs may act as the innate counterparts of Th1, Th2, and Th17 cells, yet they lack antigen receptors [43]. While allergens presented by dendritic cells induce the differentiation of CD4+ naïve T-cells into Th2 cells, cytokines secreted by lung epithelial cells, such as IL-33, IL-25, and thymic stromal lymphopoietin (TSLP) directly activate ILCs $[43,44]$. Our results display that both T cells and ILCs seem to contribute to the production of IL-5 and IL-13 when OVA in alum induced asthma, suggesting both immune response pathways of Th2 cells and ILCs can be therapeutic targets for preventing or treating asthma.

Among the Th2 cell-related cytokines, IL-4 plays a crucial role in the differentiation of naïve T cells to Th2 cells. PGT reduced the total levels of IL-5 and IL-13 in the lung, but not IL-4. Furthermore, the mRNA level of GATA-3, the signature transcription factor of Th2 cells, was not affected by PGT. These results suggest that the main target of PGT's immune-modulation was not dependent on the classical Th2 response that is activated by the introduction of allergens by DCs to naïve CD4+ T cells. Although a significant reduction in T-bet was observed in the PGT treatment group, it is less likely to be due to Th1/Th2 dysregulation, as the levels of IFN- $\gamma$ remained unchanged. Moreover, no significant difference in the levels of $I L-10$ between to OVA-challenged groups suggests that $T$ regulatory (Treg) cells were not the main target of the effect of PGT. Therefore, the reduced levels of IL-5 and IL-13 producing cells could be attributed to the modulatory effect of PGT on an ILC pathway.

Indistinguishable population differences of $\mathrm{CD} 4+\mathrm{T}$ cells among the three mice groups and modest decreases in the populations of both IL-5+-and IL-13+ CD4+ T cells in PGTtreated group in comparison to PBS-treated group provide more concrete evidence for the modulating effect of PGT on the ILC pathway. Our results provide insufficient evidence to prove the efficacy of PGT on the disease progress only by modulating the adaptive type-2 immune response. Instead, efficacy of PGT was reflected in a significant reduction in the population of IL-5+ ILCs, which explains the reduced levels of total IL-5 in the lungs of PGT-treated mice, and even further, reduced disease severity. There is growing evidence that ILCs can act upstream of the immune pathway involving adaptive type 2-immune response [45]. ILC2-deficient mice lacked the ability to induce the adaptive type 2 -immune response in response to the papain allergen [42]. While large amounts of IL-13 and IL-5 were produced by ILC2 under papain stimulation, change in the level of IL-4 was negligible; the mechanism of papain-induced Th2 responses was independent of IL-4. IL-13 produced by ILC acted as a main promoter of Th2 cell differentiation in the draining 
lymph nodes [42]. Coincidingly, our results suggest a role of PGT on production of IL-5 and IL-13 by ILC under OVA stimulation, which then interferes with induction of the Th2 responses and eosinophils, ultimately reducing the disease severity.

We hypothesized that orally administered PGT might directly affect the lungs through the bloodstream, and as a result, the levels of alarmin cytokines secretion by lung epithelial cells under allergen stimulation will be altered. The alarmin cytokines, such as IL-33 and TSLP, activate and expand the ILC2, which then will produce IL-5 and IL-13 to induce eosinophil activation and other phenotypic changes. Significant reduction in il-33 expression in PGT-treated MLE-12 cells under papain stimulation, suggest a role of PGT in regulating IL-33 production and in earlier stages of allergic asthma development. IL-33 is an important cytokine for the regulation of both the innate and adaptive immunity. It stimulates Th2 differentiation of naïve $\mathrm{CD} 4^{+} \mathrm{T}$ lymphocytes in an IL-4 independent manner, enhancing IL-5 and IL-13 production [46]. It also regulates development and the function of ILC2, as IL-13 production in chronic rhinosinusitis with nasal polyps is largely dependent on epithelial cell-derived IL-33 and IL-33-responsive ILC [47]. Our results suggest that PGT may directly act on lung epithelial cells and down-regulate their IL-33 production, leading to downregulation of the $\mathrm{T}_{\mathrm{H}}$ response and ILC response, and overall disease development.

Taken together, our results showed the effectiveness of PGT as herbal remedies to control the development of OVA-induced asthma. We showed the reducing effects of PGT on type 2 immunity and lung eosinophil infiltration in OVA-induced allergic asthma. Additionally, we successfully identified that PGT lowers ILCs and CD4+ populations which produce IL-5 and IL-13 in an IL-4 independent manner, which results in lowering eosinophil recruitment in the lungs, leading to decreasing the overall disease severity. We used OVA to induce a strong Th2 response, our results suggest that PGT may be act on upstream of Th2 response by inducing IL-33 production and ILCs.

\section{Conclusions}

In conclusion, the results suggest the possibility of using PGT as an alternative treatment to asthma. It is the first study to evaluate the mechanism of PGT in the reduction in airway infection. In the future, the bioactive compounds in the PGT mixture will be identified, and the protective effects of PGT will be carried out in non Th2-type asthma models.

Supplementary Materials: The following are available online at https:/ / www.mdpi.com/2076-3 921/10/1/6/s1, Figure S1: Gating strategy for flow cytometry, Table S1: PCR primers used in this study, Table S2: Full chemical components of PGT analyzed by non-targeted UPLC/MS system.

Author Contributions: Conceptualization, H.Y.K. and H.J.Y.; mouse experiments, S.Y., S.S., and H.J.Y.; flow cytometry analysis, J.W.S.; data curation, S.S. and S.K.; writing-original draft preparation, S.Y. and H.J.Y.; writing—review and editing, S.S., J.W.S., S.K., H.Y.K. and H.J.Y.; supervising, H.Y.K. and H.J.Y.; funding acquisition, H.J.Y. All authors have read and agreed to the published version of the manuscript.

Funding: This work was carried out with the support of the National Research Foundation of Korea (NRF) (NRF-2015R1A2A1A10054078 and NRF-2015R1D1A1A02062267) and the "K-BIO KIURI Center program (Project number 2020M3H1A1073304)".

Conflicts of Interest: The authors declare no conflict of interest.

\section{References}

1. Masoli, M.; Fabian, D.; Holt, S.; Beasley, R.; Global Initiative for Asthma (GINA) Program. The global burden of asthma: Executive summary of the GINA Dissemination Committee report. Allergy 2004, 59, 469-478. [CrossRef] [PubMed]

2. Bahadori, K.; Doyle-Waters, M.M.; Marra, C.; Lynd, L.; Alasaly, K.; Swiston, J.; FitzGerald, J.M. Economic burden of asthma: A systematic review. BMC Pulm. Med. 2009, 9, 24. [CrossRef] [PubMed]

3. Nunes, C.; Pereira, A.M.; Morais-Almeida, M. Asthma costs and social impact. Asthma Res. Pract. 2017, 3, 1. [CrossRef] [PubMed]

4. Braman, S.S. The global burden of asthma. Chest 2006, 130, 4S-12S. [CrossRef]

5. Asthma, G.I.f. Global strategy for asthma management and prevention. Updated. 2018. 
6. $\quad$ Bousquet, J.; Chanez, P.; Lacoste, J.Y.; Barnéon, G.; Ghavanian, N.; Enander, I.; Venge, P.; Ahlstedt, S.; Simony-Lafontaine, J.; Godard, P. Eosinophilic inflammation in asthma. N. Engl. J. Med. 1990, 323, 1033-1039. [CrossRef]

7. Foster, P.S.; Hogan, S.P.; Ramsay, A.J.; Matthaei, K.I.; Young, I.G. Interleukin 5 deficiency abolishes eosinophilia, airways hyperreactivity, and lung damage in a mouse asthma model. J. Exp. Med. 1996, 183, 195-201. [CrossRef]

8. Bosnjak, B.; Stelzmueller, B.; Erb, K.J.; Epstein, M.M. Treatment of allergic asthma: Modulation of Th2 cells and their responses. Respir. Res. 2011, 12, 114. [CrossRef]

9. Barnes, P.J. Th2 cytokines and asthma: An introduction. Respir. Res. 2001, 2, 64-65. [CrossRef]

10. Wenzel, S.E. Asthma phenotypes: The evolution from clinical to molecular approaches. Nat. Med. 2012, 18, 716. [CrossRef]

11. Rosenberg, H.F.; Phipps, S.; Foster, P.S. Eosinophil trafficking in allergy and asthma. J. Allergy Clin. Immunol. 2007, 119, 1303-1310. [CrossRef]

12. Walter, D.M.; McIntire, J.J.; Berry, G.; McKenzie, A.N.; Donaldson, D.D.; DeKruyff, R.H.; Umetsu, D.T. Critical role for IL-13 in the development of allergen-induced airway hyperreactivity. J. Immunol. 2001, 167, 4668-4675. [CrossRef] [PubMed]

13. Webb, D.C.; McKenzie, A.N.; Koskinen, A.M.; Yang, M.; Mattes, J.; Foster, P.S. Integrated signals between IL-13, IL-4, and IL-5 regulate airways hyperreactivity. J. Immunol. 2000, 165, 108-113. [CrossRef] [PubMed]

14. Olin, J.T.; Wechsler, M.E. Asthma: Pathogenesis and novel drugs for treatment. BMJ 2014, 349, g5517. [CrossRef] [PubMed]

15. Kerrebijn, K.F.; van Essen-Zandvliet, E.; Neijens, H.J. Effect of long-term treatment with inhaled corticosteroids and beta-agonists on the bronchial responsiveness in children with asthma. J. Allergy Clin. Immunol. 1987, 79, 653-659. [CrossRef]

16. Barnes, P.J.; Pedersen, S.; Busse, W.W. Efficacy and safety of inhaled corticosteroids: New developments. Am. J. Respir. Crit. Care Med. 1998, 157, S1-S53. [CrossRef]

17. Guilbert, T.W.; Morgan, W.J.; Zeiger, R.S.; Mauger, D.T.; Boehmer, S.J.; Szefler, S.J.; Bacharier, L.B.; Lemanske, R.F., Jr.; Strunk, R.C.; Allen, D.B. Long-term inhaled corticosteroids in preschool children at high risk for asthma. N. Engl. J. Med. 2006, 354, 1985-1997. [CrossRef]

18. Busse, W.; Corren, J.; Lanier, B.Q.; McAlary, M.; Fowler-Taylor, A.; Della Cioppa, G.; van As, A.; Gupta, N. Omalizumab, anti-IgE recombinant humanized monoclonal antibody, for the treatment of severe allergic asthma. J. Allergy Clin. Immunol. 2001, 108, 184-190. [CrossRef]

19. Milgrom, H.; Fick, R.B., Jr.; Su, J.Q.; Reimann, J.D.; Bush, R.K.; Watrous, M.L.; Metzger, W.J. Treatment of allergic asthma with monoclonal anti-IgE antibody. N. Engl. J. Med. 1999, 341, 1966-1973. [CrossRef]

20. Djukanovic, R.; Wilson, S.J.; Kraft, M.; Jarjour, N.N.; Steel, M.; Chung, K.F.; Bao, W.; Fowler-Taylor, A.; Matthews, J.; Busse, W.W. Effects of treatment with anti-immunoglobulin E antibody omalizumab on airway inflammation in allergic asthma. Am. J. Respir. Crit. Care Med. 2004, 170, 583-593. [CrossRef]

21. Jutel, M.; Agache, I.; Bonini, S.; Burks, A.W.; Calderon, M.; Canonica, W.; Cox, L.; Demoly, P.; Frew, A.J.; O’hehir, R. International consensus on allergy immunotherapy. J. Allergy Clin. Immunol. 2015, 136, 556-568. [CrossRef]

22. Cazzola, M.; Matera, M.G. Novel long-acting bronchodilators for COPD and asthma. Br. J. Pharmacol. 2008, 155, 291-299. [CrossRef] [PubMed]

23. Cazzola, M.; Page, C.P.; Calzetta, L.; Matera, M.G. Pharmacology and therapeutics of bronchodilators. Pharmacol. Rev. 2012, 64, 450-504. [CrossRef] [PubMed]

24. Martinez, F.D. New insights into the natural history of asthma: Primary prevention on the horizon. J. Allergy Clin. Immunol. 2011, 128, 939-945. [CrossRef] [PubMed]

25. Warner, S.M.; Knight, D.A. Airway modeling and remodeling in the pathogenesis of asthma. Curr. Opin. Allergy Clin. Immunol. 2008, 8, 44-48. [CrossRef]

26. Lipworth, B.J. Systemic adverse effects of inhaled corticosteroid therapy: A systematic review and meta-analysis. Arch. Intern. Med. 1999, 159, 941-955. [CrossRef]

27. Kelly, H.W.; Sternberg, A.L.; Lescher, R.; Fuhlbrigge, A.L.; Williams, P.; Zeiger, R.S.; Raissy, H.H.; Van Natta, M.L.; Tonascia, J.; Strunk, R.C. Effect of inhaled glucocorticoids in childhood on adult height. N. Engl. J. Med. 2012, 367, 904-912. [CrossRef]

28. Partridge, M.R.; van der Molen, T.; Myrseth, S.-E.; Busse, W.W. Attitudes and actions of asthma patients on regular maintenance therapy: The INSPIRE study. BMC Pulm. Med. 2006, 6, 13. [CrossRef]

29. Rabe, K.; Vermeire, P.; Soriano, J.; Maier, W. Clinical management of asthma in 1999: The Asthma Insights and Reality in Europe (AIRE) study. Eur. Respir. J. 2000, 16, 802-807. [CrossRef]

30. Lan, W.; Zhaojun, Z.; Zesheng, Z. Characterization of antioxidant activity of extracts from Flos Lonicerae. Drug Dev. Ind. Pharm. 2007, 33, 841-847. [CrossRef]

31. Ku, S.-K.; Seo, B.-I.; Park, J.-H.; Park, G.-Y.; Seo, Y.-B.; Kim, J.-S.; Lee, H.-S.; Roh, S.-S. Effect of Lonicerae Flos extracts on reflux esophagitis with antioxidant activity. World J. Gastroenterol. WJG 2009, 15, 4799. [CrossRef]

32. Lee, Y.-C.; Lee, J.-C.; Seo, Y.-B.; Kook, Y.-B. Liriopis tuber inhibit OVA-induced airway inflammation and bronchial hyperresponsiveness in murine model of asthma. J. Ethnopharmacol. 2005, 101, 144-152. [CrossRef] [PubMed]

33. Hu, J.-R.; Jung, C.-J.; Ku, S.-M.; Jung, D.-H.; Ku, S.-K.; Choi, J.-S. Antitussive, expectorant, and anti-inflammatory effects of Adenophorae Radix powder in ICR mice. J. Ethnopharmacol. 2019, 239, 111915. [CrossRef]

34. Roh, S.-S.; Kim, S.-H.; Lee, Y.-C.; Seo, Y.-B. Effects of radix adenophorae and cyclosporine A on an OVA-induced murine model of asthma by suppressing to T cells activity, eosinophilia, and bronchial hyperresponsiveness. Mediat. Inflamm. 2008, 781425. [CrossRef] 
35. Huang, M.-H.; Wang, B.-S.; Chiu, C.-S.; Amagaya, S.; Hsieh, W.-T.; Huang, S.-S.; Shie, P.-H.; Huang, G.-J. Antioxidant, antinociceptive, and anti-inflammatory activities of Xanthii Fructus extract. J. Ethnopharmacol. 2011, 135, 545-552. [CrossRef] [PubMed]

36. Won, A.-N.; Kim, S.A.; Ahn, J.Y.; Han, J.-H.; Kim, C.-H.; Lee, J.-H.; Kim, D.-I. HO-1 Induction by Selaginella tamariscina extract inhibits inflammatory response in lipopolysaccharide-stimulated RAW 264.7 Macrophages. Evid. Based Complement. Altern. Med. 2018, 7816923. [CrossRef] [PubMed]

37. Han, Y.; Jung, H.W.; Lee, J.Y.; Kim, J.S.; Kang, S.S.; Kim, Y.S.; Park, Y.-K. 2, 5-dihydroxyacetophenone isolated from Rehmanniae Radix Preparata inhibits inflammatory responses in lipopolysaccharide-stimulated RAW264. 7 macrophages. J. Med. Food 2012, 15, 505-510. [CrossRef] [PubMed]

38. Lloyd, C.M.; Hessel, E.M. Functions of T cells in asthma: More than just T H 2 cells. Nat. Rev. Immunol. 2010, 10, 838. [CrossRef]

39. Vock, C.; Hauber, H.-P.; Wegmann, M. The other T helper cells in asthma pathogenesis. J. Allergy 2010, 519298. [CrossRef]

40. Lloyd, C.M.; Hawrylowicz, C.M. Regulatory T cells in asthma. Immunity 2009, 31, 438-449. [CrossRef]

41. Kidd, P. Th1/Th2 balance: The hypothesis, its limitations, and implications for health and disease. Altern. Med. Rev. 2003, 8, 223-246.

42. Halim, T.Y.; Steer, C.A.; Mathä, L.; Gold, M.J.; Martinez-Gonzalez, I.; McNagny, K.M.; McKenzie, A.N.; Takei, F. Group 2 innate lymphoid cells are critical for the initiation of adaptive T helper 2 cell-mediated allergic lung inflammation. Immunity 2014, 40, 425-435. [CrossRef] [PubMed]

43. Cortez, V.S.; Robinette, M.L.; Colonna, M. Innate lymphoid cells: New insights into function and development. Curr. Opin. Immunol. 2015, 32, 71-77. [CrossRef] [PubMed]

44. Camelo, A.; Rosignoli, G.; Ohne, Y.; Stewart, R.A.; Overed-Sayer, C.; Sleeman, M.A.; May, R.D. IL-33, IL-25, and TSLP induce a distinct phenotypic and activation profile in human type 2 innate lymphoid cells. Blood Adv. 2017, 1, 577-589. [CrossRef]

45. Eberl, G.; Colonna, M.; Di Santo, J.P.; McKenzie, A.N. Innate lymphoid cells: A new paradigm in immunology. Science 2015, 348, aaa6566. [CrossRef] [PubMed]

46. Kurowska-Stolarska, M.; Kewin, P.; Murphy, G.; Russo, R.C.; Stolarski, B.; Garcia, C.C.; Komai-Koma, M.; Pitman, N.; Li, Y.; McKenzie, A.N. IL-33 induces antigen-specific IL-5+ T cells and promotes allergic-induced airway inflammation independent of IL-4. J. Immunol. 2008, 181, 4780-4790. [CrossRef]

47. Shaw, J.L.; Fakhri, S.; Citardi, M.J.; Porter, P.C.; Corry, D.B.; Kheradmand, F.; Liu, Y.-J.; Luong, A. IL-33-responsive innate lymphoid cells are an important source of IL-13 in chronic rhinosinusitis with nasal polyps. Am. J. Respir. Crit. Care Med. 2013, 188, 432-439. [CrossRef] 